\title{
Partial Discharge Activity in Polymeric Cable Insulation under High Voltage AC and DC
}

\author{
Euan A. Morris \\ EPSRC CDT in Future Power Networks and Smart Grids, UK \\ euan.a.morris@strath.ac.uk
}

\author{
W.H. Siew \\ University of Strathclyde, UK \\ wh.siew@strath.ac.uk
}

\begin{abstract}
The focus of this paper is to report on analysis of partial discharge characteristics in insulation samples containing artificially created voids under AC and DC excitation. Samples were initially tested under $\mathrm{AC}$ conditions to determine that the artificial void was the dominant source of PD. Once this was proven the samples were tested under DC to generate knowledge on PD under these conditions. The results were analyzed, with differences between AC and DC PD in artificial voids determined. The impact of these differences on potential methods of PD detection are also briefly discussed.
\end{abstract}

Index Terms-HVDC, Partial Discharge, Condition Monitoring, Polymeric Insulation, Cables

\section{INTRODUCTION}

$\mathrm{E}$ LECTRICAL cables are among the most fundamental components of any power grid, from large subsea international interconnectors, to the 'last mile' providing consumers with their electricity supply. The size, cost and current carrying capability are the main considerations when designing and selecting a cable, and in this regard the insulation of these cables is as fundamental as the conductor.

Partial discharge (PD) measurement is becoming increasingly vital in monitoring the condition of cable insulation, providing valuable information about the health of the insulation, and predicting when insulation is likely to fail.

Partial discharge under AC conditions has been a subject of study for several decades[1] with several commercial solutions available today[2].

However, the increasing use of high voltage DC links, for subsea, or long land-based connections provides motivation for the increased use of PD monitoring on cables operating under HVDC.

However, despite the increased intensity of research into PD in HVDC cables, there are significant knowledge gaps, preventing the practical application of PD monitoring techniques to HVDC cables.

This paper discusses a method for the creation and PD testing of artificial voids in cable insulation samples previous used under AC conditions for use under DC excitation. Results are presented under both conditions.

\section{THEORY}

\section{A. Partial Discharge}

Partial discharge, is defined by IEC standard 60270[3] as "localised electrical discharge that only partially bridge the insulation between conductors". PD is produced when there is a defect within a cable, either due to a manufacturing issue, degradation over time, or due to damage during maintenance.

\section{B. AC vs DC Partial Discharge}

Much of the initial research into PD under DC conditions was performed at the Technical University of Delft, summarised in [4]. This determined several key differences between PD under AC and DC conditions, finding that DC discharges occurred less frequently, were of smaller magnitude, and, in general, were more of symptom of defects than a cause of them.

Other research has looked into DC testing under a range of conditions [5]-[8], establishing common patterns for corona, surface and void discharges.

\section{Cable Insulation}

There are a range of insulation options for HVDC cables[9]. In the past mass-impregnated cables have been used; in modern cables, polymeric insulation is utilized.

The polymer utilized for this paper was low-density polyethylene (LDPE). LDPE has a long history of use in power cable insulation, and shares the ethylene group with the more recently popular cross-linked polyethylene (XLPE)[10]. The material had a relative permittivity of 2.275 .

\section{METHOD}

For this paper, analysis is performed on the characteristics of PD in artificially-crated voids in polymer samples under both $\mathrm{AC}$ and $\mathrm{DC}$ excitation. The AC testing was performed to determine the both inception voltage, and to ensure the dominant source of PD was the artificial void.

\section{A. Test Rig}

The experimental test-rig (Fig 1.) consisted of two brass electrodes of $7.5 \mathrm{~mm}$ radius. The bottom electrode is connected to earth and is fixed. The top electrode is connected to the HV source, and can be adjusted up or down with precision.

This work was supported through the EPSRC Centre for Doctoral 
The electrodes are rounded to reduce edge effects, and are cleaned and polished after every use. The rest of the rig is constructed from ABS.

The rig is placed in a tank of mineral oil, to reduce the chance of additional discharge effects. The temperature of the oil is monitored throughout the testing

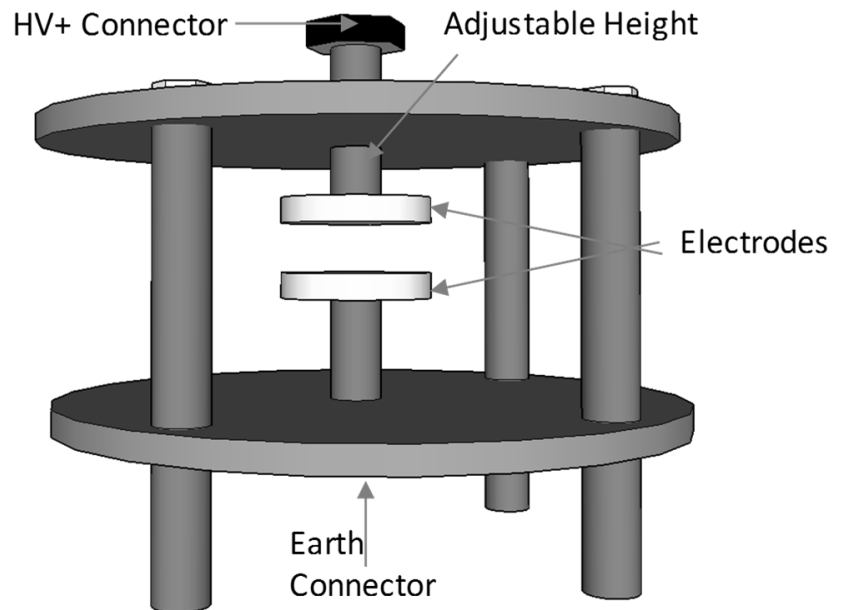

Fig. 1. Test rig used for applying voltage to artificial void samples

\section{B. Test Samples}

The test samples (Fig 2.) were created by layering samples of LDPE measuring $15 \mathrm{~mm} \times 15 \mathrm{~mm}$. Seven layers were used, giving a total thickness of $0.35 \mathrm{~mm}$. A circular section of diameter $1 \mathrm{~mm}$ is removed from the central layer. The layers are then placed between the electrodes and the electrodes adjusted until the gap is the same as the size of the sample $(0.35$ $\mathrm{mm})$.

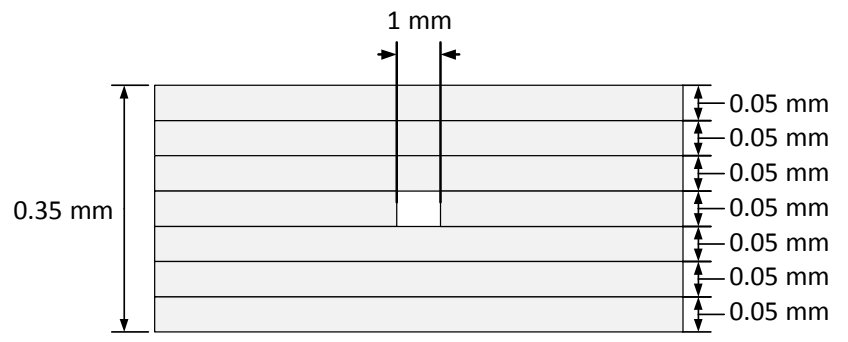

Fig. 2. Representation of layered artificial void sample. There are seven layers made from $0.05 \mathrm{~mm}$ thin film LDPE. (Not to scale.)

A similar method has been utilised under AC conditions in [11] and allows for good control over void size and location in materials utilised in power cable insulation. Although a cylindrical void is produced rather than a spherical void.

\section{AC Test Method}

A IEC 60270 standard-complaint PD measurement system with a bandwidth of 100-400 kHz (Fig 3.) was used to perform AC testing.

\section{0 kV Transformer}

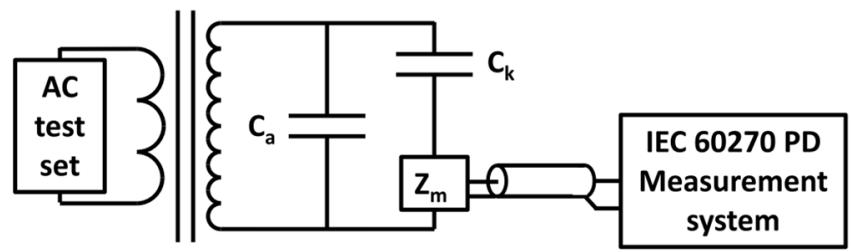

Fig. 3. AC test circuit including IEC 60270 PD detection system. The circuit includes the $\mathrm{AC}$ generator; transformer; $\mathrm{C}_{\mathrm{k}}$, a coupling capacitor; $\mathrm{Ca}$, the sample under test; and a measuring impedance connected to the detection system. Diagram from [18].

A voltage is applied, starting at the minimum allowed by the equipment, $2.9 \mathrm{kV}$, this is steadily increased in steps of $100 \mathrm{~V}$ every ten minutes until PD inception (defined as at least one PD event per minute) occurs. Once the PD inception is found the voltage is increased to $10 \%$ higher than this, and held for two hours. PD is measured for the entirety of this two hour test period.

\section{DC Test Method}

The same measurement system (Fig 4.) was used to perform DC testing, with a high frequency current transformer (bandwidth $100 \mathrm{kHz}$ to $20 \mathrm{MHz}$ ) used as the PD sensor.

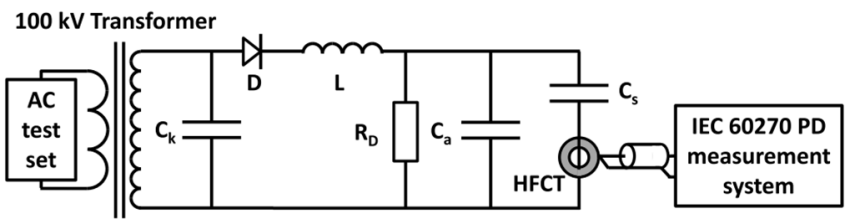

Fig. 4. DC test circuit including IEC 60270 PD detection system. The circuit includes the $\mathrm{AC}$ generator; transformer; $\mathrm{C}_{\mathrm{k}}$ and $\mathrm{C}_{\mathrm{S}}$, two coupling capacitors; $\mathrm{Ca}$, the sample under test; $\mathrm{D}$, an $\mathrm{HV}$ diode; $\mathrm{L}$, an $\mathrm{HV}$ inductor; $\mathrm{R}_{\mathrm{D}}$, a resistive divider for voltage measurement; and an HFCT connected to the detection system. Diagram from [18].

\section{RESUltS}

\section{A. PD Inception}

From Paschen's law, it is possible to derive an expected value of breakdown strength, given a gas pressure and gap length.

$$
V_{b d}=P\left(A+\left[B /(P L)^{C}\right]\right)
$$

With an assumed value of air pressure, $\mathrm{P}$, of $100 \mathrm{kPa}$ (standard atmosphere pressure), a value of $L$ as $0.35 \mathrm{~mm}$, and values of $A$, $\mathrm{B}$ and $\mathrm{C}$ from the Paschen's curve values for air at standard pressure[12].

From this it is possible to determine an expected value for PD inception[13].

$$
V i=\frac{V_{B D}}{\varepsilon_{r}}\left[L_{S}+L_{V}\left(\varepsilon_{r}-1\right)\right]
$$

Where $V_{\mathrm{BD}}$ is found from (1), $\mathrm{L}_{\mathrm{S}}$ is the thickness of the solid insulation $(0.3 \mathrm{~mm})$, and $\mathrm{LV}_{\mathrm{V}}$ is the thickness of the void $(0.05 \mathrm{~mm})$. From this the expected PD inception voltage would be $2.2 \mathrm{kV}$

In actuality, the PD inception voltage is also influenced by the presence of a free electron. As such the average value found under $\mathrm{AC}$ conditions was slightly higher at $3.2 \mathrm{kV}$, and the value found under DC conditions was significantly higher at 9.1 $\mathrm{kV}$. 
TABLE I

EXPECTED AND ACTUAL PD INCEPTION VOLTAGE

\begin{tabular}{|c|c|c|c|c|}
\hline \multirow{2}{*}{} & \multicolumn{2}{|c|}{ AC } & \multicolumn{2}{c|}{ DC } \\
\cline { 2 - 5 } & Calculated & Excitation & Calculated & Excitation \\
\hline PDIV & $2.2 \mathrm{kV}$ & $3.2 \mathrm{kV}$ & $2.2 \mathrm{kV}$ & $9.1 \mathrm{kV}$ \\
\hline
\end{tabular}

B. AC PD Analysis

The primary goal of the AC testing was to confirm the dominant source of PD detected was that of the artificial void, by comparison of PD plots with established literature.

Fig 5 shows the phase-resolved PD plot for the average data obtained over the first hour of the testing period. The PD signals are centered around two phases, between $0-90^{\circ}$ degrees, and between $180-270^{\circ}$.

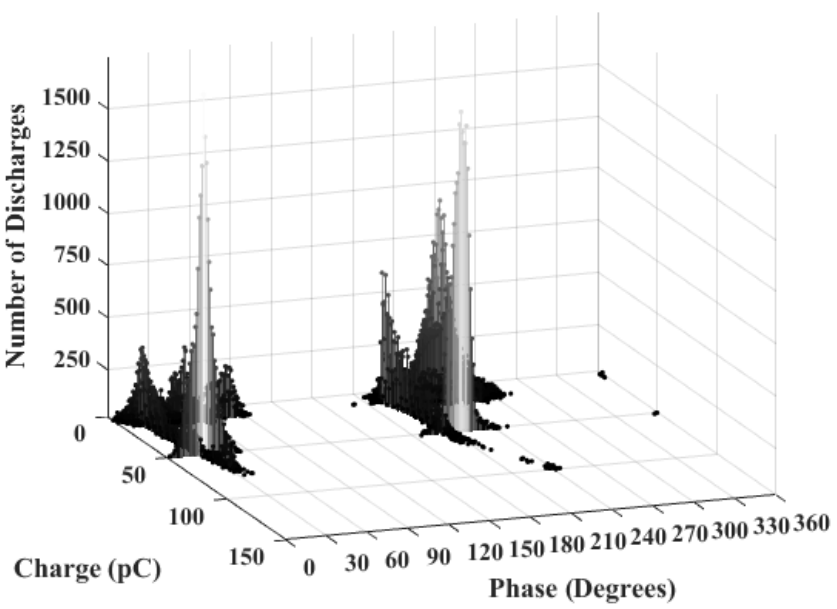

Fig. 5. Ф-Q-N pattern for single void at $3.5 \mathrm{kV}$ for $0-1$ hours

This 'rabbit-ear' pattern is a common indicator of a void type discharge. The 'peaks' occur in advance of the voltage peaks (at around $30^{\circ}$ and $210^{\circ}$ ) which is also indicative of internal discharge.

Fig 6 shows the PRPD plot for the entire 2-hour test period.

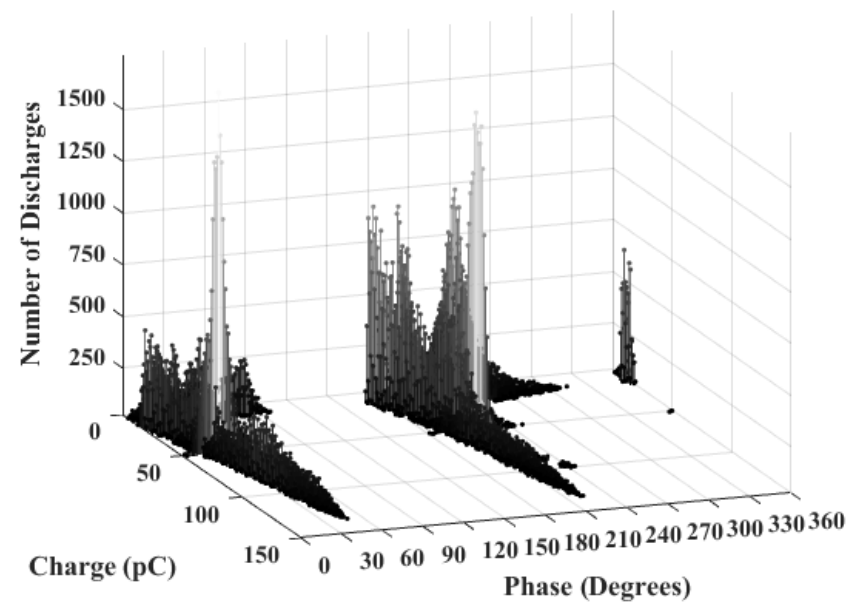

Fig. 6.. Ф-Q-N pattern for single void at $3.5 \mathrm{kV}$ for $0-2$ hours
The 'rabbit-ear' pattern remains prominent over the entire test period, with discharges of a greater charge being more likely to occur in the second hour of testing.

Fig 7 shows the cumulative charge over the 2-hour testing period. There is steady increase in PD charge for the initial 20 minutes of the testing period, with a relatively stable period from 20 to 80 minutes, with an increase found again from 80 minutes onwards.

The 'stopping and starting' of PD is also associated with a void discharge[14].

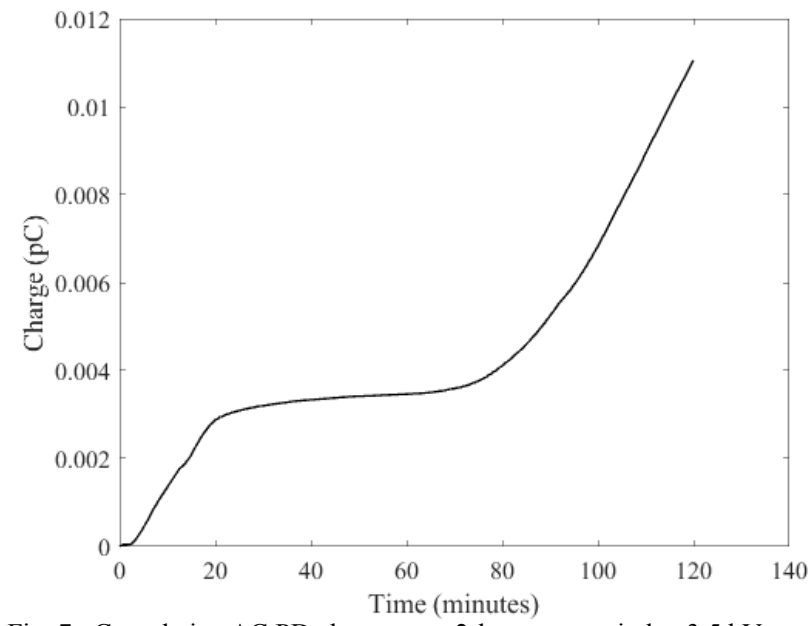

Fig. 7. Cumulative AC PD charge over 2-hour test period at $3.5 \mathrm{kV}$

Overall, results from the $\mathrm{AC}$ testing were as expected for a single void in LDPE insulation[14]-[18], [12]. This validates the test set-up and methodology and allows for knowledge generation under DC conditions.

\section{DC PD Analysis}

Fig 8 shows the pulse charge histogram for the DC testing over the 2-hour period.

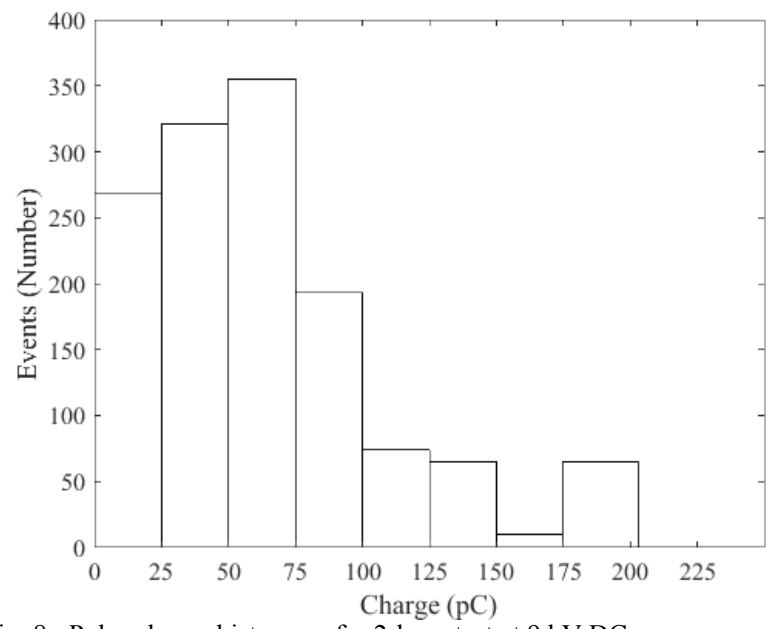

Fig. 8. Pulse charge histogram for 2 -hour test at $9 \mathrm{kV}$ DC

The charge magnitudes were found to be in roughly the same range as those under $\mathrm{AC}$ conditions. However, the number of discharges were significantly lower, and the applied voltage was significantly higher. 


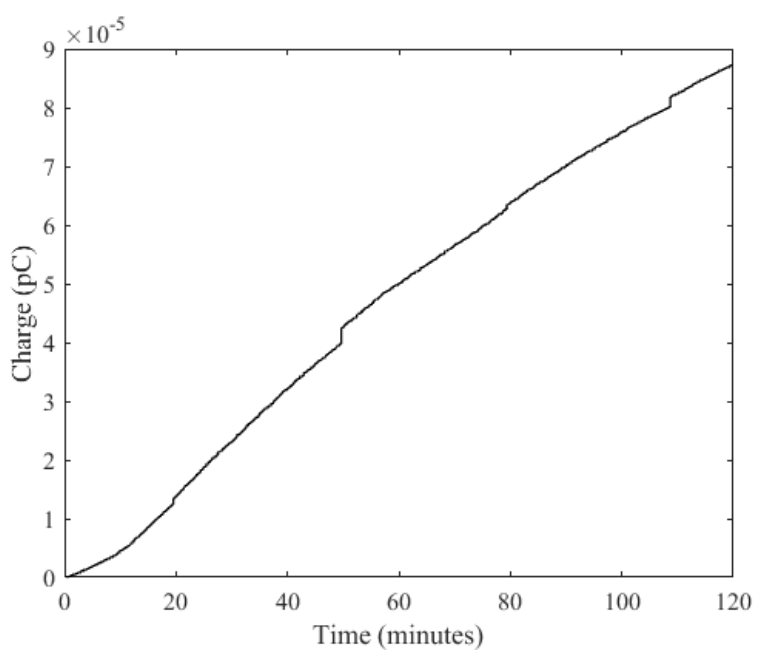

Fig. 9. Cumulative DC PD charge over 2-hour test period at $9 \mathrm{kV}$

There was a relatively steady increase in cumulative charge over the 2-hour test period. The total cumulative charge over the 2-hour test period was significantly lower than under AC excitation.

\section{CONCLUSIONS}

This paper has presented analysis on DC partial discharge performed via a method now demonstrated to produce expected results under DC conditions.

Experimental work completed in this paper has demonstrated the potential limitations of using DC partial discharge detection in a similar manner to $\mathrm{AC}$ detection, owing to the overall smaller and less frequent discharges.

Significantly the inception voltage for the DC samples was nearly three times greater than that under $\mathrm{AC}$, which confirms previous indications that $\mathrm{DC} \mathrm{PD}$ is unlikely to be a significant source of cable degradation, however the utility of DC PD as a diagnosis tool were not addressed.

\section{FUTURE WORK}

As discussed above, the choice of insulating material is a key one in designing or selecting cable, therefore one consideration for future work would be to consider the impact that the choice of polymeric insulation has on the detected PD patterns. The ease of which condition monitoring through the detection of PD signals can be applied could help in deciding which cable to select.

Additionally, determining the feasibility of DC PD detection over longer distances should also be a critical focus. In this regard, determining PD patterns that are found in cable samples under DC conditions would be a sensible next step in continuing this project.

The overall aim should be to assess the attenuation of these signals in cables, with consideration of noise reduction methods, to fully assess the practical limitations of DC PD detection in the condition monitoring of HVDC cables.

\section{ACKNOWLEDGEMENT}

The authors would like to thank: from the University of Strathclyde- Edward Corr, Rong Tang, and Brian Stewart; from Glasgow Caledonian University- Donald Hepburn; and from Scottish \& Southern Electricity Networks- Geary Cleary, and David Stroud, for their advice on the direction and implementation of the project.

\section{REFERENCES}

[1] R. Bartnikas, "Partial Discharges: Their Mechanism, Detection and Measurement," IEEE Trans. Dielectr. Electr. Insul., vol. 9, no. 5, pp. 763-808, 1997.

[2] HVPD, "HVPD Products and Services Catalogue." [Online]. Available: www.hvpd.co.uk. [Accessed: 25-May-2017].

[3] International Electrotechnical Commission - Technical Commitee 42 -High-voltage and high-current test techniques, IEC 60270:2000 - High-voltage test techniques - Partial discharge measurements, no. 3. 2000, pp. 1-99.

[4] P. H. F. Morshuis and J. J. Smit, "Partial discharges at de voltage: Their mechanism, detection and analysis," IEEE Trans. Dielectr. Electr. Insul., vol. 12, no. 2, pp. 328-340, Apr. 2005.

[5] U. Fromm and P. H. F. Morshuis, "Partial Discharge Classification at DC Voltage," in IEEE 5th Annual Conference of Conduction and Breakdown in Solid Dielectrics, 1995, pp. 403-407.

[6] M. R. Rahimi, R. Javadinezhad, and M. Vakilian, "DC Partial Discharge Characteristics for Corona, Surface and Void Discharges," pp. 260-263, 2015.

[7] P. H. F. Morshuis and J. Beyer, "Quality assessment of HVDC components by PD analysis," Conf. Electr. Insul. Dielectr. Phenom. (CEIDP), Annu. Rep., vol. 2, pp. 542-545, 1997.

[8] J. Beyer, "Space charge and partial discharge phenomena in HVDC devices," Technische Universiteit Delf, 2002.

[9] G. Mazzanti and M. Marzinotto, "Main Principles of HVDC Extruded Cable Design," in Extruded Cables for High-Voltage Direct-Current Transmission:Advances in Research and Development, Wiley-IEEE Press, 2013.

[10] G. Mazzanti and M. Marzinotto, "Fundamentals of HVDC Cable Transmission," in Extruded Cables for High-Voltage Direct-Current Transmission:Advances in Research and Development, 1 st ed., Wiley-IEEE Press, 2013, p. 384.

[11] D. Adhikari, "Analysis of Partial Discharge Activity in Void Defects in Polymer Insulation," Glasgow Caledonian University, 2013.

[12] D. Adhikari, D. M. Hepburn, and B. G. Stewart, "Analysis of partial discharge characteristics in artificially created voids," Univ. Power Eng. Conf. (UPEC), 2010 45th Int., pp. 1-4, 2010.

[13] B. Ramachandra and R. S. Nema, "Characterisation of Partial Discharge Pulses in Artificial Voids in Polypropylene Films Used in Capacitors," in International Symposium on Electrical Insulation, 1996, pp. 517-520.

[14] T. Mizutani, T. Kondo, and K. Nakao, "Change in partial discharge properties of a void in LDPE," 1999 Annu. Rep. Conf. Electr. Insul. Dielectr. Phenom. (Cat. No.99CH36319), pp. 257-260, 1999.

[15] C. S. Kim, T. Hirase, and T. Mizutani, "PD frequency characteristics for a void bounded with LDPE," Electr. Insul. Dielectr. Phenomena, 2002 Annu. Rep. Conf., pp. 712-715, 2002.

[16] C. S. Kim, T. Kondo, and T. Mizutani, "Change in PD Pattern with Aging," IEEE Trans. Dielectr. Electr. Insul., vol. 11, no. 1, pp. 1318, 2004.

[17] Y. Sekii and T. Sugai, "A Study on the Deterioration of LDPE and Epoxy Insulation by Partial Discharge," in Conference on Electrical Insulation and Dielectric Phenomena, 1997.

[18] E. Corr and W. H. Siew, "Analyses of partial discharges in dielectric samples under DC excitation," Proc. Univ. Power Eng. Conf., vol. 2015-Novem, pp. 1-6, 2015. 